https://helda.helsinki.fi

Toxic lifespan of the synthetic opioid $U-47,700$ in Finland verified by re-analysis of UPLC-TOF-MS data

Kriikku, Pirkko

2019-07

Kriikku , P , Pelander , A , Rasanen , I \& Ojanperä , I 2019 , ' Toxic lifespan of the synthetic opioid U-47,700 in Finland verified by re-analysis of UPLC-TOF-MS data ' , Forensic Science International , vol. 300 , pp. 85-88 . https://doi.org/10.1016/j.forsciint.2019.04.030

http://hdl.handle.net/10138/318788

https://doi.org/10.1016/j.forsciint.2019.04.030

publishedVersion

Downloaded from Helda, University of Helsinki institutional repository.

This is an electronic reprint of the original article.

This reprint may differ from the original in pagination and typographic detail.

Please cite the original version. 


\title{
Toxic lifespan of the synthetic opioid U-47,700 in Finland verified by re-analysis of UPLC-TOF-MS data
}

\author{
Pirkko Kriikku a,b,* , Anna Pelander ${ }^{\mathrm{a}}$, Ilpo Rasanen ${ }^{\mathrm{a}}$, Ilkka Ojanperä ${ }^{\mathrm{a}, \mathrm{b}}$ \\ ${ }^{a}$ Forensic Toxicology Unit, National Institute for Health and Welfare, Helsinki, Finland \\ ${ }^{\mathrm{b}}$ Department of Forensic Medicine, University of Helsinki, Helsinki, Finland
}

\section{A R T I C L E I N F O}

\section{Article history:}

Received 15 January 2019

Received in revised form 17 April 2019

Accepted 24 April 2019

Available online 1 May 2019

\section{Keywords:}

Time-of-flight mass spectrometry

U-47,700

Novel psychoactive substances

Synthetic opioids

Retrospective data-analysis

\begin{abstract}
A B S T R A C T
$\mathrm{U}-47,700$ is a synthetic opioid that emerged on the novel psychoactive substance market a few years ago. After incorporating the substance into the urine UPLC-TOF-MS screening used in post-mortem toxicology, the drug was detected in 10 autopsy cases within routine case work. In all cases, the cause of death was accidental poisoning by U-47,700 alone or in combination with other psychoactive substances. The concentration of U-47,700 in the blood samples ranged between $0.15-2.0 \mathrm{mg} / \mathrm{L}$ with a median of $0.30 \mathrm{mg} / \mathrm{L}$. In one of the cases with a U-47,700 concentration of $0.27 \mathrm{mg} / \mathrm{L}$, no other psychoactive substances were detected.

The stored TOF-MS analytical data from the year preceding the incorporation of U-47,700 into the screening was reprocessed in order to search for more positive cases. The data-independent acquisition of the original screening allowed for retrospective re-analysis of the full-scan data without additional experiments on the actual sample. The retrospective data-analysis revealed two additional cases positive for U-47,700.

The first mention of U-47,700 on a Finnish internet discussion forum was in March 2015. After having been detected in several death cases, the drug was put under national control in November 2016 and the last fatality occurred in 2017. The toxic lifespan of U-47,700 thus lasted for approximately 2 years in Finland.

Forensic and clinical laboratories need to rapidly adjust their screening procedures in order to adapt to the continuously expanding field of novel psychoactive substances. Retrospective data-analysis is a practical tool for monitoring the emergence of new substances onto the market.
\end{abstract}

(C) 2019 Elsevier B.V. All rights reserved.

\section{Introduction}

Opioids are commonly abused by users of illegal drugs, and they account for the majority of fatal poisonings worldwide [1,2]. In Finland, the opioid most commonly implicated as the cause of death is buprenorphine, a semi-synthetic partial agonist at the $\mu$ opioid receptor, whereas heroin abuse and deaths are rare. Also other medicinal opioids used in the treatment of pain are frequently detected in fatal poisoning cases, often together with other psychoactive substances.

In addition to medicinal opioids, recent years have brought new opioids onto the illicit drug market; opioids that have never been approved for medical use. One of these is U-47,700 (3,4-dichloro$N$-[2-(dimethylamino)cyclohexyl]- $N$-methylbenzamide) (Fig. 1 ), a highly selective $\mu$-receptor agonist originally developed by the

\footnotetext{
* Corresponding author at: Forensic Toxicology Unit, National Institute for Health and Welfare, Helsinki, Finland.

E-mail address: pirkko.kriikku@thl.fi (P. Kriikku).
}

company Upjohn in 1970s [3]. Since 2016, several reports have been published on serious adverse effects associated with $U$ 47,700, including death cases [4-15].

The emergence of new psychoactive substances (NPS) is a challenge for forensic and clinical laboratories since new substances enter the drug market in an ever escalating pace. Acquiring reference material for each NPS is hardly sensible due to financial reasons or due to the fact that these substances are not readily available. In traditional toxicological screening it is only possible to find those substances that are looked for. It is complicated to estimate whether a certain NPS is of relevance in one's own setting and should be incorporated into the screening. Using time-of-flight mass spectrometry (TOF) with data-independent acquisition, the full precursor ion data set as well as the full fragment ion data set are acquired in a single run. Thus it is possible to revisit previously analysed raw data and look for new information without the need to run the samples again.

LC-TOFMS has gained popularity in the forensic field due to the accurate mass and high mass resolution capabilities combined with easily expandable reference databases but relatively few 


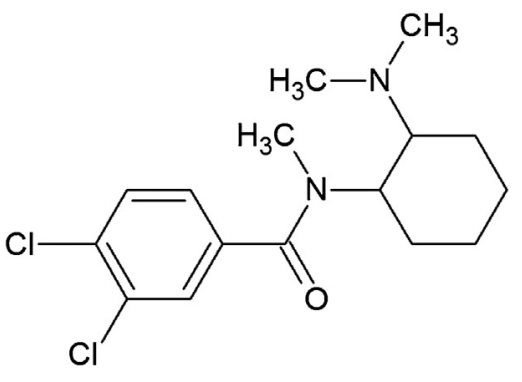

Fig. 1. Structure of $U-47,700$.

reports are available of realizing the possibility to retrospectively reprocess the historic data $[13,16-18]$. In this project we aimed to study the lifespan of $U-47,700$ in Finland, taking advantage of the possibility to retrospectively reanalyse the stored data.

\section{Material and methods}

Urine and femoral blood samples from unexpected death cases were collected at autopsies and stored refrigerated until analysis.

\subsection{Adding $U-47,700$ to the TOF-MS database}

A sample of seized $U-47,700$ was generously provided by the Finnish Customs Laboratory in March 2016. A standard solution with the approximate concentration of $1 \mu \mathrm{g} / \mathrm{mL}$ of $U-47,700$ was injected into the system twice (two parallel injections). The precursor exact mass, retention time and assigned fragment ions information of the substance was added to the TOF-MS analyte database. The following criteria were met for the two injections: $\Delta \mathrm{Rt}<0.3 \mathrm{~min}$, mass precision of the precursor ion $<3 \mathrm{mDa}$, and mass precision of the qualifier ion $<5 \mathrm{mDa}$. As customary for updating the analyte database, the fragmentation pattern of U47,700 was further confirmed by the ACD/MS Fragmenter software (Advanced Chemistry Development, Toronto, Canada) and the Smart Formula 3D feature of Bruker Data Analysis software (Bruker Daltonics GmbH, Bremen, Germany).

The exact mass of the precursor protonated molecule added to the database was $\mathrm{m} / \mathrm{z} 329.1182$, and the exact masses of the characteristic fragment ions were $\mathrm{m} / \mathrm{z} 284.0603$ and m/z 203.9977. The primary fragment ( $\mathrm{m} / \mathrm{z} 284.0603)$ used as qualifier ion for U47,700 is also a fragment of the structural isomer AH-7921 another abused opioid. However, in the current procedure, these two analytes are chromatographically separated (retention time difference $>0.35 \mathrm{~min}$ ). Ion ratios of the two substances are different and the fragment 284.0603 is not the most abundant fragment of $\mathrm{AH}-7921$. Consequently, the qualifier ions assigned for AH-7921 $(\mathrm{m} / \mathrm{z} 172.9552$ and 189.9821$)$ are different from those of $U-47,700$. In addition, $\mathrm{m} / \mathrm{z} 189.9821$ is unique for $\mathrm{AH}-7921$, which further minimizes the risk of false identification.

After the first detection of the substance in biological samples, an official reference standard was purchased from Chiron (Trondheim, Norway) enabling appropriate quantitative analysis.

\subsection{Sample preparation and qualitative screening with UPLC-TOFMS}

Urine samples were screened for $U-47,700$ by ultra-high performance liquid chromatography coupled with high-resolution time-of-flight mass spectrometry (UPLC-TOFMS). The screening method is described in detail elsewhere [19]. In short, after hydrolysis and solid phase extraction, the extracts were dissolved in a mixture of methanol and $0.1 \%$ formic acid (45:55) without concentrating the samples. The extracts were injected into the
UPLC-TOFMS system consisting of a Waters Acquity UPLC coupled with a Bruker MicroTOF Q II. Data were acquired in full-scan MS and bbCID (broad-band collision-induced dissociation) MS modes by switching the collision energy between $8 \mathrm{eV}$ (precursor MS data acquisition) and $30 \mathrm{eV}$ (fragment bbCID MS data acquisition).

The UPLC-TOFMS screening provided full-scan data that was subsequently processed against the in-house analyte database consisting of hundreds of medicinal drugs, drugs of abuse, NPS and metabolites. The principles of the database search have been published elsewhere [19].

\subsection{Quantitative analysis with GC-MS}

Quantification of U-47,700 in femoral blood and urine was performed by gas chromatography-mass spectrometry (GC-MS), using a method originally developed for the determination of MDPV [20]. The GC-MS analysis was performed by selected ion monitoring, using four ions ( $\mathrm{m} / \mathrm{z} 125$ (target), 84, 145, and 173) for $\mathrm{U}-47,700$. The heptafluorobutyric acid derivative of MDMA-d5 (m/ z 254, 210) was used as an internal standard.

Linearity of the method was studied by constructing calibration curves in blood and urine, consisting of seven concentration points over the range of $0.02-2.5 \mathrm{mg} / \mathrm{L}$ with five parallel measurements in each point. The correlation coefficient $\left(r^{2}\right)$ was $\geq 0.991$. Intra-day accuracy (bias) and precision was $<11 \%$ and $<6 \%$ CV (at $0.02-$ $2.5 \mathrm{mg} / \mathrm{L}$ ), respectively. Between-day accuracy and precision were measured on seven separate days over a period of four weeks. Between-day accuracy (bias) at 0.1 and $1.0 \mathrm{mg} / \mathrm{L}$ was $10 \%$ and $16 \%$, respectively, and between-day precision $12 \%$ and $16 \% \mathrm{CV}$, respectively. The limits of detection (LOD) and quantification (LOQ) were 0.01 and $0.02 \mathrm{mg} / \mathrm{L}$, respectively

The GC-MS-method was able to chromatographically separate $\mathrm{U}-47,700$ from the structural isomer $\mathrm{AH}-7921$ (retention time difference $0.35 \mathrm{~min}$ ).

\subsection{Retrospective data-analysis}

Retrospective analysis of the stored TOF-MS data for the oneyear period prior to inclusion of $U-47,700$ in the database was conducted in the same way as the original data analysis, but the analyte database had in the meantime been updated with new analytes, including $U-47,700$.

Reanalysis of the raw data was rather time-consuming due to the high number of cases and, consequently, the volume of data to be reanalysed. The software was let to reprocess the data overnight, one month at the time.

\section{Results and discussion}

$\mathrm{U}-47,700$ was first detected in a post-mortem sample in April 2016; one month after the drug had been included in the screening. $\mathrm{U}-47,700$ was subsequently detected in seven other post-mortem cases in 2016. Consequently, U-47,700 was controlled under the Narcotics Act in Finland in November 2016. In 2017, the drug was detected twice but there were no positive autopsy cases in 2018. Details of the ten cases positive for U-47,700 are given in Table 1 . In all of the 10 cases, the cause of death was accidental poisoning by U47,700 alone or in combination with other psychoactive substances.

All of the deceased positive for $U-47,700$ were male, and their mean age (range) was 26 (23-31) years. The median (range) blood concentration of $U-47,700$ was $0.30(0.15-2.0) \mathrm{mg} / \mathrm{L}$. In most cases other psychoactive drugs were detected along with U-47,700. According to the background information, in most cases the deceased had a history of drug abuse. The concentrations detected in these 10 cases were similar to those reported by Mohr et al. [6], Rojek et al. [14] and Smith et al. [15] who found median U-47,700 
Table 1

Details of U-47,700-positive cases in 2016 and 2017.

\begin{tabular}{|c|c|c|c|c|c|c|}
\hline \multirow[t]{2}{*}{ Case } & \multirow[t]{2}{*}{ Age } & \multirow[t]{2}{*}{ Gender } & \multirow{2}{*}{$\begin{array}{l}\text { BAC } \\
\mathrm{g} / \mathrm{kg}\end{array}$} & \multicolumn{2}{|c|}{ Concentration of $\mathrm{U}-47,700$} & \multirow[t]{2}{*}{ Other drugs detected in blood (mg/L) } \\
\hline & & & & Blood (mg/L) & Urine $(\mathrm{mg} / \mathrm{L})$ & \\
\hline 1 & 23 & Male & 3.00 & 0.22 & 0.02 & - \\
\hline 2 & 27 & Male & - & 0.32 & 0.03 & MDMA 2,4; amphetamine 0,67 ; pregabalin 40 ; alprazolam 0,006 \\
\hline 3 & 28 & Male & - & 0.19 & posit & N-MBZP 0,092; BZP 0,0081; m-CPP 0,020; phenazepam 0,26; alprazolam 0,034; \\
\hline 4 & 24 & Male & - & 0.27 & 0.40 & 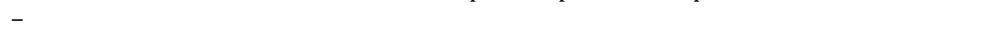 \\
\hline 5 & 29 & Male & 2.00 & 0.19 & 0.06 & Buprenorphine $0.53 \mu \mathrm{g} / \mathrm{L}$; 7-aminoclonazepam 0.18; pregabalin 3.9; cannabis positive \\
\hline 6 & 23 & Male & 0.75 & 0.37 & 0.10 & 7-aminoclonazepam 0.16 \\
\hline 7 & 25 & Male & - & 0.15 & 0.23 & Pregabalin 19; alprazolam 0.013; lorazepam 0.011; THC $6.4 \mu \mathrm{g} / \mathrm{L}$ \\
\hline 8 & 25 & Male & - & 2.00 & 0.89 & Buprenorphine $1 \mu \mathrm{g} / \mathrm{L} ;$ 7-aminoclonazepam 0.14 \\
\hline 9 & 31 & Male & - & 0.64 & 0.57 & $\begin{array}{l}\alpha-P V P 0.34 \text {; THC } 1.1 \mu \mathrm{g} / \mathrm{L} \text {; pregabalin } 11 \text {; alprazolam } 0.030 \text {; tramadol } 0.47 \text {; diazepam } 0.059 \text {; } \\
\text { olanzapine } 0.42\end{array}$ \\
\hline 10 & 23 & Male & - & 0.96 & 2.20 & Amphetamine 0.17; 7-aminoclonazepam 0.24; alprazolam 0.009; buprenorphine $<0.5 \mu \mathrm{g} / \mathrm{L}$ \\
\hline R1 & 27 & Male & - & - & Posit & Etizolam 0.040; 7-aminoclonazepam 0.083; ТHC-COOH $20 \mu \mathrm{g} / \mathrm{l}$ \\
\hline R2 & 32 & Male & - & - & Posit & Amphetamine 0.32 ; etizolam $<0.025$ \\
\hline
\end{tabular}

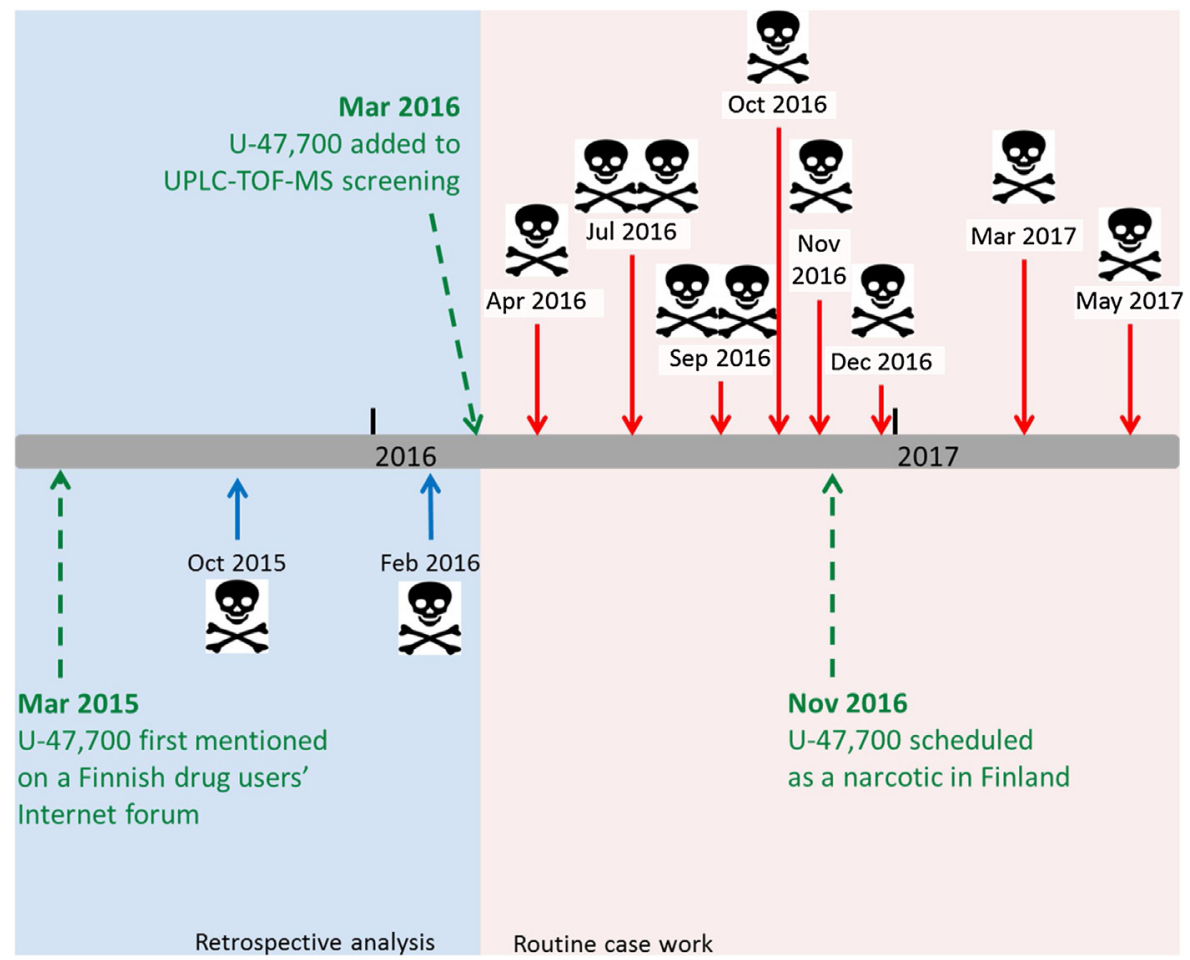

Fig. 2. U-47,700 in Finland.

PM blood concentrations of $0.247 \mathrm{mg} / \mathrm{L} \quad(\mathrm{N}=16), 0.306 \mathrm{mg} / \mathrm{L}$ $(\mathrm{N}=12)$, and $0.126 \mathrm{mg} / \mathrm{L}(\mathrm{N}=15)$ respectively.

Among the studied cases, there was one case in which no other psychoactive substances, besides U-47,700, were detected (Case 4, Table 1). The blood concentration of $U-47,700$ in this case $(0.27 \mathrm{mg} / \mathrm{L})$ did not significantly differ from the median $U-47,700$ concentration. However, regardless of the blood concentration, the toxicological significance of detecting $U-47,700$ or any other opioid is profoundly connected to the state of opioid tolerance the victim may have possessed, as well as the route of administration and other findings. Thus, defining a fatal concentration for a strong opioid, such as U47,700 , is considered somewhat meaningless.

Retrospective re-analysis of the acquired TOF-MS data was performed for all samples screened for illegal drugs within a oneyear period before inclusion of U-47,700 in the screening method. A total of 1836 samples were reprocessed. The procedure resulted in two additional positive findings of U-47,700. Details on these two cases are presented in Table 1 (R1 \& R2) and the toxic lifespan of $U-47,700$ in post-mortem investigations in Finland is illustrated on a timeline in Fig. 2. Unfortunately, at the time of the reprocessing, the original sample material was no longer available and thus no quantitative results are available. Interestingly, in both of the retrospectively detected cases, etizolam was detected together with U-47,700.

Retrospective re-analysis is a tool often mentioned as a useful option but relatively seldom used in forensic laboratories. To our knowledge, only in a handful of cases retrospective re-analysis has been successfully used to detect drugs in previously analysed biological samples. Partridge et al. was able to detect several NPS in a death case after having updated the in-house database [13]. Noble et al. screened thousands of blood samples for fentanyl derivatives using retrospective re-analysis of previously acquired data [18]. Retrospective data processing has also been used to screen for metabolites in samples in which the parent compound has already been identified [17,21,22].

There are several factors affecting the lifespan of an NPS. Considering the total number of all different NPS reported, only a 
few of them have gained considerable prevalence or media attention. It has been shown that the legal status of a substance in the end-users' country has a considerable influence on the interest in the drug and on the corresponding harms [23,24].

Drug marketplaces on the hidden web are increasingly used for anonymous sale of drugs [25], and the earliest indication of the possible appearance of a new substance might indeed be evidenced on the hidden web [26]. One study found that vendors selling NPS had short lifespans, and while individual NPS had longer lifespans, only a quarter of the studied substances were generally available over a period of one year [25]. Post-mortem toxicology usually contributes to the monitoring of emerging NPS only when their use has become prevalent in the society. However, potent opioids are exceptional in this respect, as has been evidenced with the case of 3-methylfentanyl in Finland, where all the findings of the drug were from fatalities that occurred within a short period of time [27].

Another important factor affecting the lifespan of a particular NPS is the drug supply in the country of origin. Concerning U47,700 , the substance was added to China's list of controlled substances as of July 1, 2017, which coincides with the end of the toxic epidemic in Finland.

In addition to laboratory measures, a number of other methods for monitoring the appearance and use of NPS are being used. These include e.g. monitoring the online user forums, user questionnaires, information from poisons information services, and international early warning systems [28]. As demonstrated in the case of U-47,700 in Finland and in the few studies published before, retrospective data-analyses can be a valuable tool in assessing the time point at which the drug has entered the market $[13,16]$.

\section{Conclusion}

A series of cases positive for an NPS opioid U-47,700 was detected in post-mortem investigations within a relatively short time period prompting the idea of retrospectively re-analysing the data before the first detection. The re-analysis resulted in two additional cases. The post-targeted screening approach enabled relatively easy access to the full-scan data acquired before incorporating the substance into the screening. Retrospective data analysis can be especially useful when monitoring the lifespan of NPS in clinical and forensic settings.

\section{Author contribution statement}

Pirkko Kriikku conceived of the presented idea, performed the retrospective analyses and wrote the manuscript with input from all other authors. Anna Pelander contributed with in-depth knowledge of the instrumentation and data analysis procedures. Ilpo Rasanen preformed the quantitative analyses. Ilkka Ojanperä aided in interpreting the results especially with regards to the concept of NPS lifespan. All authors discussed the results and contributed to the final manuscript.

\section{References}

[1] https://www.drugabuse.gov/related-topics/trends-statistics/overdose-deathrates. (Accessed 3 November 2017).

[2] http://emcdda.europa.eu/publications/edr/trends-developments/2017. (Accessed 3 November 2017).

[3] J. Szmuszkovicz, P.F. Von Voigtlander, Benzeneacetamide amines: structurally novel non-mu opioids, J. Med. Chem. 25 (1982) 1125-1126.

[4] S.P. Elliott, S.D. Brandt, C. Smith, The first reported fatality associated with the synthetic opioid 3, 4-dichloro- $N$-[2-(dimethylamino) cyclohexyl]- $N$-methylbenzamide (U-47700) and implications for forensic analysis, Drug Test. Anal. 8 (2016) 875-879.
[5] V. Coopman, P. Blanckaert, G. Van Parys, S. Van Calenbergh, J. Cordonnier, A case of acute intoxication due to combined use of fentanyl and 3, 4-dichloro- $N$ [2-(dimethylamino) cyclohexyl]-N-methylbenzamide (U-47700), Forensic Sci. Int. 266 (2016) 68-72.

[6] A.L. Mohr, M. Friscia, D. Papsun, S.L. Kacinko, D. Buzby, B.K. Logan, Analysis of novel synthetic opioids U-47700, U-50488 and furanyl fentanyl by LC-MS/MS in postmortem casework, J. Anal. Toxicol. 40 (2016) 709-717.

[7] P. Armenian, A. Olson, A. Anaya, A. Kurtz, R. Ruegner, R.R. Gerona, Fentanyl and a novel synthetic opioid U-47700 masquerading as street "Norco" in Central California: a case report, Ann. Emerg. Med. 69 (2017) 87-90.

[8] K. Domanski, K.C. Kleinschmidt, J.M. Schulte, S. Fleming, C. Frazee, A Menendez, K. Tavakoli, Two cases of intoxication with new synthetic opioid, U-47700, Clin. Toxicol. 55 (2017) 46-50.

[9] A. Schneir, I.G. Metushi, C. Sloane, D.J. Benaron, R.L. Fitzgerald, Near death from a novel synthetic opioid labeled U-47700: emergence of a new opioid class, Clin. Toxicol. 55 (2017) 51-54

[10] I.M. McIntyre, R.D. Gary, S. Joseph, R. Stabley, A fatality related to the synthetic opioid U-47700: postmortem concentration distribution, J. Anal. Toxicol. 41 (2017) 158-160.

[11] M.J. Jones, B.S. Hernandez, G.C. Janis, S.J. Stellpflug, A case of U-47700 overdose with laboratory confirmation and metabolite identification, Clin. Toxicol. 55 (2017) 55-59.

[12] M. Dziadosz, M. Klintschar, J. Teske, Postmortem concentration distribution in fatal cases involving the synthetic opioid U-47700, Int. J. Legal Med. 131 (2017) 1555.

[13] E. Partridge, S. Trobbiani, P. Stockham, C. Charlwood, C. Kostakis, A case study involving U-47700, diclazepam and flubromazepam-application of retrospective analysis of HRMS data, J. Anal. Toxicol. 42 (2018) 655-660.

[14] S. Rojek, A. Romańczuk, K. Kula, K. Synowiec, M. Kłys, Quantification of U47700 and its metabolites: $N$-desmethyl-U-47700 and N,N-didesmethyl-U47700 in 12 autopsy blood samples employing SPE/LC-ESI-MS-MS, Forensic Toxicol. (2019) epublished before print.

[15] C.R. Smith, M.T. Truver, M.J. Swortwood, Quantification of U-47700 and its metabolites in plasma by LC-MS/MS, J. Chromatogr. B 1112 (2019) 41-47.

[16] K.G. Shanks, T. Dahn, G. Behonick, A. Terrell, Analysis of first and second generation legal highs for synthetic cannabinoids and synthetic stimulants by ultra-performance liquid chromatography and time of flight mass spectrometry, J. Anal. Toxicol. 36 (2012) 360-371.

[17] D. Favretto, S. Vogliardi, G. Stocchero, A Nalesso, M. Tucci, C. Terranova, S.D. Ferrara, Determination of ketamine and norketamine in hair by micropulverized extraction and liquid chromatography-high resolution mass spectrometry, Forensic Sci. Int. 226 (2013) 8-93.

[18] C. Noble, P. Weihe Dalsgaard, S. Stybe Johansen, K. Linnet, Application of a screening method for fentanyl and its analogues using UHPLC-QTOFMS with data-independent acquisition (DIA) in MSE mode and retrospective analysis of authentic forensic blood samples, Drug Test. Anal. 10 (2017) 651-662.

[19] M. Sundström, A. Pelander, V. Angerer, M. Hutter, S. Kneisel, I. Ojanperä, A high-sensitivity ultra-high performance liquid chromatography/high-resolution time-of-flight mass spectrometry (UHPLC-HR-TOFMS) method for screening synthetic cannabinoids and other drugs of abuse in urine, Anal. Bioanal. Chem. 405 (2013) 8463-8474.

[20] I.A. Ojanperä, P.K. Heikman, I.J. Rasanen, Urine analysis of 3,4-methylenedioxypyrovalerone in opioid-dependent patients by gas chromatography-mass spectrometry, Ther. Drug Monit. 33 (2011) 257-263.

[21] G. Frison, S. Frasson, F. Zancanaro, G. Tedeschi, L. Zamengo, Detection of 3 methylmethcathinone and its metabolites 3-methylephedrine and 3-methylnorephedrine in pubic hair samples by liquid chromatography-high resolution/high accuracy Orbitrap mass spectrometry, Forensic Sci. Int. 265 (2016) 131-137.

[22] S. Vikingsson, M. Josefsson, H. Green, Identification of AKB-48 and 5F-AKB48 metabolites in authentic human urine samples using human liver microsomes and time of flight mass spectrometry, J. Anal. Toxicol. 39 (2015) 426-435.

[23] A. Ledberg, The interest in eight new psychoactive substances before and after scheduling, Drug Alcohol Depend. 152 (2015) 73-78.

[24] P. Kriikku, J. Rintatalo, K. Pihlainen, J. Hurme, I. Ojanperä, The effect of banning MDPV on the incidence of MDPV-positive findings among users of illegal drugs and on court decisions in traffic cases in Finland, Int. J. Legal Med. 129 (2015) $741-749$.

[25] E. Wadsworth, C. Drummond, P. Deluca, The dynamic environment of crypto markets: the lifespan of new psychoactive substances (NPS) and vendors selling NPS, Brain Sci. 8 (2018) 46.

[26] J.M. Corkery, L. Orsolini, D. Papanti, F. Schifano, From concept(ion) to life after death/the grave: the 'natural' history and life cycle(s) of novel psychoactive substances (NPS), Hum. Psychopharmacol. 32 (2017) 2566.

[27] I. Ojanperä, M. Gergov, I. Rasanen, P. Lunetta, S. Toivonen, E. Tiainen, E. Vuori, Blood levels of 3-methylfentanyl in 3 fatal poisoning cases, Am. J. Forensic Med. Pathol. 27 (2006) 328-331.

[28] M. Evans-Brown, R. Sedefov, Responding to new psychoactive substances in the European union: early warning, risk assessment, and control measures, in: H.H. Maurer, S.D. Brandt (Eds.), New Psychoactive Substances, Springer, Cham, 2018, pp. 3-49. 